\title{
Kajian Pembuatan Oksida Grafit untuk Produksi Oksida Grafena dalam Jumlah Besar
}

\author{
Norman Syakir, Rhesti Nurlina, Syafiul Anam, Annisa Aprilia, Sahrul Hidayat, Fitrilawati ${ }^{\#}$ \\ Departemen Fisika Universitas Padjadjaran \\ Jalan Raya Jatinangor Km 21 Jatinangor Sumedang Jawa Barat \\ \#fitrilawati@phys.unpad.ac.id
}

\begin{abstract}
Abstrak - Oksida grafit (GO) telah berhasil disintesis menggunakan metode Hummers dari serbuk grafit dengan pelarut asam sulfat $\left(\mathrm{H}_{2} \mathrm{SO}_{4}\right)$, natrium nitrat $\left(\mathrm{NaNO}_{3}\right)$, kalium permanganat $\left(\mathrm{KMnO}_{4}\right)$, dan hidrogen peroksida $\left(\mathrm{H}_{2} \mathrm{O}_{2}\right) . \mathrm{Hasil}$ sintesis berupa pasta dicuci dengan asam klorida $(\mathrm{HCl})$ dan akuades berulang-ulang untuk mendapatkan GO yang relatif murni. Pasta tersebut selanjutnya dikeringkan dan digerus untuk karakterisasi EDS (Energy Dispersive Spectroscopy), difraksi XRD (X-ray Difraction), dan spektroskopi FTIR (Fourier Transform Infrared). Untuk mengupas lembaran GO menjadi lapisan lebih tipis, pasta yang dihasilkan tersebut didispersikan dalam akuades, kemudian disonikasi serta disentrifugasi. Hasil yang didapat dikarakterisasi dengan menggunakan spektroskopi UV-Vis. Hasil karakterisasi sampel serbuk menunjukkan telah terjadi perubahan struktur grafit dengan terbentuknya gugus-gugus fungsional oksigen.
\end{abstract}

Kata kunci: grafit, oksida grafit, metoda Hummers, oksida grafena

\begin{abstract}
Graphyte oxide (GO)has successfully synthesized using Hummers method from graphite powder using, sulfuric acids $\left(\mathrm{H}_{2} \mathrm{SO}_{4}\right)$, sodium nitrate $\left(\mathrm{NaNO}_{3}\right)$, kalium permanganat $\left(\mathrm{KMnO}_{4}\right)$, and peroxide acids $\left(\mathrm{H}_{2} \mathrm{O}_{2}\right)$. The result seem as $G O$ pasta then it was rinsed using chloric acids $(\mathrm{HCl})$ and aquades for many times to get a pure GO pasta. Following this, the pasta was dried then grind to form pure GO powder for characterisation purpose using EDS (Energy Dispersive Spectroscopy), XRD diffraction (X-ray Difraction), and FTIR (Fourier Transform Infrared) spectroscopy. To exfoliate GO flakes to become more thinner as GO sheets, the pure GO pasta was dispersed in aquades follow by sonication and sentrifugation. The result was characterized using UV-Vis absorbance spectroscopy. The characterization results show that the structure of graphite power has been change to graphite oxide, indicated by forming the functional cluster of oxygen.
\end{abstract}

Key words: graphyte, graphyte oxide, Hummers methods, graphene oxide

\section{PENDAHULUAN}

Grafena (Graphene) merupakan material dua dimensi monoatomik dari satu lapis grafit yang ditemukan pada tahun 2004 oleh Andre K. Geim dan Konstantin Novoselov [1]. Saat ini grafena banyak diinvestigasi oleh para peneliti dari berbagai bidang karena tertarik dengan keunggulan dan sifat unik yang dimilikinya. Dengan ketebalan sekitar satu atom karbon, grafena memiliki transparansi optik hingga 97,7\% [2]. Meskipun sangat tipis, kekuatan grafena melebihi baja. Ikatan kovalen antar karbon yang kuat menyebabkan grafena sulit untuk diregangkan, sehingga memiliki modulus Young hingga 1,1 TPa [3]. Struktur yang terdiri dari lapisan-lapisan membuat grafena sangat konduktif dengan mobilitas pembawa muatan hingga $200.000 \mathrm{~cm}^{2} \mathrm{~V}^{-1} \mathrm{~s}^{-1}$ [4] dan konduktivitas termal hingga $5.300 \mathrm{Wm}^{-1} \mathrm{~K}^{-1}$ [5]. Dengan keunggulan sifat yang dimilikinya, grafena berpotensi besar untuk dikembangkan sebagai komponen perangkat elektronik.

Grafena dapat disintesis melalui pengolahan grafit, menjadi lembaran-lembaran tunggal grafena seperti yang diilustrasikan pada Gambar 1 [6]. Secara sederhana grafit dioksidasi menjadi oksida grafit (GO), kemudian lembaran-lembaran oksida grafit tersebut dikelupas (exfoliated) dalam air hingga terbentuk oksida grafena.

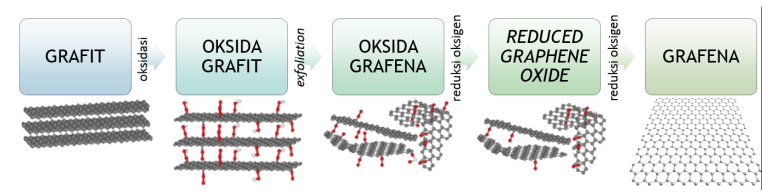

Gambar 1. Skema pembuatan grafena dari grafit [6]

Konsentrasi oksigen dalam oksida grafena dapat direduksi hingga habis meninggalkan lapisan grafena. Oksida grafena diyakini dapat menjadi prekursor yang menjanjikan untuk produksi grafena dalam skala besar.

Untuk memperoleh oksida grafena, maka sebelumnya harus dibentuk GO. Graphite oxide yang dikenal sebagai graphitic acid telah ditemukan sejak tahun 1859 setelah Brodie mengoksidasi Ceylon graphite dengan campuran kalium klorida $\left(\mathrm{KClO}_{3}\right)$ dan asam nitrat $\left(\mathrm{HNO}_{3}\right)$ [7]

Sejak itu ada berbagai cara dikembangkan untuk memperoleh GO. Staudenmaier mengembangkan metode Brodie dengan menambahkan sulfida pada pelarut oksidanya. Namun menurut Hofmann, Frenzel, dan Hamdi, metode Staudenmaier membutuhkan waktu oksidasi yang lebih lama dan menghasilkan produk samping yang berbahaya [7]. Pada tahun 1958, William S. Hummers dan Richard E. Offeman mempublikasikan 
metode oksidasi untuk merubah grafit menjadi GO [7]. Metode yang kemudian dikenal sebagai metode Hummers tersebut mengoksidasi grafit dengan cara mereaksikan grafit dengan kalium permanganat $\left(\mathrm{KMnO}_{4}\right)$ dan natrium nitrat $\left(\mathrm{NaNO}_{3}\right)$ dalam larutan asam sulfat $\left(\mathrm{H}_{2} \mathrm{SO}_{4}\right)$. Metode Hummers dinilai lebih baik daripada dua metode sebelumnya karena pada saat proses oksidasi tidak mengeluarkan gas $\mathrm{ClO}_{2}$. Gas ini harus ditangani dengan hati-hati karena sangat berbahaya dan dapat menimbulkan ledakan. Selain itu, proses oksidasi dapat berlangsung lebih cepat dengan suhu lebih rendah. Produk akhir GO dari metode Hummers memiliki tingkat oksidasi yang lebih tinggi dibandingkan dengan produk akhir dari metode Staudenmaier [7]. Bahan-bahan yang digunakan dalam metode Hummers lebih mudah untuk didapat dan tidak terlalu berbahaya seperti dalam metode Staudenmaier. Oleh karena itu, metode Hummers lebih sering digunakan untuk mensintesis GO.

Pada makalah ini akan diuraikan hasil sintesis oksida grafit dari serbuk grafit dengan menggunakan metoda Hummers dan hasil karakterisasinya.

\section{EKSPERIMEN}

Sintesis GO dilakukan dengan menggunakan metode Hummers, yang diawali dengan memasukkan larutan asam sulfat $\left(\mathrm{H}_{2} \mathrm{SO}_{4}, 95-97 \%, M E R C K\right)$ ke dalam gelas ukur berisi magnetic bar yang ditempatkan dalam ice bath. Ke dalam larutan tersebut dimasukkan serbuk natrium nitrat $\left(\mathrm{NaNO}_{3}, 30 \%\right.$, AnalaR $)$ dan diaduk hingga menjadi homogen. Setelah itu ke dalam nya ditambahkan serbuk grafit murni sambil diaduk hingga homogen lagi. Berikutnya serbuk kalium permanganat $\left(\mathrm{KMnO}_{4}\right)$ ditambahkan sedikit-sedikit sambil diaduk hingga homogen dan terjadi reaksi oksidasi. Hasil reaksi yang didapat diencerkan dengan akuades dan selanjutnya ditambahkan senyawa hidrogen peroksida $\left(\mathrm{H}_{2} \mathrm{O}_{2}\right)$ sambil terus diaduk. Selanjutnya larutan tersebut diendapkan sehingga terbentuk fase padat dan cair. Bagian fase cair dibuang dan fase padat pasta diambil. Pasta ini adalah GO yan kemudian didispersikan kembali dalam akuades dan ditambahkan asam klorida $(\mathrm{HCl})$ sambil diaduk. Produk GO murni didapat melalui proses penyaringan dan selanjutnya didispersikan kembali dalam akuades. Untuk mengupas (exfoliation) GO menjadi lembaran yang lebih tipis maka dispersi GO tersebut dikenakan proses sonikasi dengan menggunakan ultrasonic bath pada suhu ruang dan dilanjutkan dengan sentrifugasi menggunakan kecepatan $2500 \mathrm{rpm}$. Proses ini dilakukan secara berulang sehingga tidak terlihat adanya serbuk yang mengendap.

Untuk karakterisasi yang memerlukan bentuk serbuk, pasta yang didapat dikeringkan dengan proses sintering, lalu dihaluskan dengan mortar keramik. Untuk studi struktur, serbuk yang diperoleh dipanaskan pada berbagai variasi suhu yaitu: $100{ }^{\circ} \mathrm{C}$ (GO100), $150{ }^{\circ} \mathrm{C}$ (GO150), $350{ }^{\circ} \mathrm{C}$ (GO350), dan $500{ }^{\circ} \mathrm{C}$ (GO500) masing-masing selama 3 jam.

Untuk mengetahui jenis-jenis atom yang terdapat dalam produk GO maka dilakukan pengukuran EDS dengan menggunakan Hitachi Tabletop Microscope TM3000. Pengukuran EDS dilakukan pada sampel GO yang belum dan yang sudah dipurifikasi. Untuk mengetahui struktur GO yang disintesis melalui proses oksidasi menggunakan metode Hummers dilakukan pengukuran XRD menggunakan XRD Philips Analytical pada rentang sudut $10^{\circ}-90^{\circ}$. Untuk mengetahui perubahan struktur ikatan yang terjadi pada grafit setelah melalui proses oksidasi dilakukan karakterisasi FTIR menggunakan Prestige 21 Shimadzu pada rentang bilangan gelombang $450-4.500 \mathrm{~cm}^{-1}$. Pengukuran absorbansi UV-Vis dilakukan pada sampel yang didispersi dalam akuades. Pengukuran dilakukan sebelum dan sesudah proses sonikasi dan sentrifugasi menggunakan spektrometer UV-Vis, T70+ UV/Vis Spectrometer dari PG Instruments Ltd.

\section{HASIL DAN PEMBAHASAN}

Hasil sintesis GO yang didapatkan berupa pasta bewarna coklat, setelah dicuci dengan akuades dan $\mathrm{HCl}$ pasta tersebut bewarna coklat kekuningan. Keefektifan metode oksidasi dapat dilihat dari perbandingan atom karbon dan oksigen pada GO. Penelitian sebelumnya melaporkan GO yang baik memiliki nilai $\mathrm{C} / \mathrm{O}$ antara 2,1 hingga 2,9 [7].

Struktur permukaan dan spektrum komposisi dari sampel GO yang dihasilkan diperlihatkan pada Gambar 2 dan 3. Hasil pengukuran menunjukkan sampel GO yang belum dipurifikasi mengandung unsur karbon (C), oksigen $(\mathrm{O})$, sulfur $(\mathrm{S})$, dan kalium $(\mathrm{K})$. Setelah GO dipurifikasi, kadar $\mathrm{K}$ hilang dan kandungan karbon dan oksigennya meningkat. Perbanding $\mathrm{C} / \mathrm{O}$ untuk sampel yang belum dipurifikasi adalah 1,5 dan setelah dipurifikasi perbandingan $\mathrm{C} / \mathrm{O}$ menjadi 2,3. Hasil tersebut menunjukkan sampel GO yang belum dipurifikasi masih mengandung sisa garam seperti kalium dan nilai $\mathrm{C} / \mathrm{O}<2,1$. Setelah dipurifikasi sisa garam dapat dihilangkan dan nilai $\mathrm{C} / \mathrm{O}>2.1$, yang menunjukkan keberhasilan proses oksidasi. Hasil ini mengkonfirmasi bahwa purifikasi merupakan tahapan penting pada pembuatan GO.

\section{Electron Image}

Image Width: $41.8 \mu \mathrm{m}$

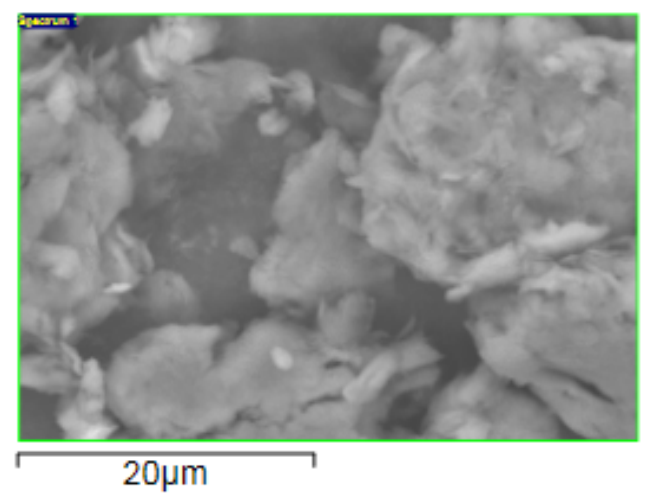

Gambar 2. Struktur permukaan oksida grafit (GO) hasil sintesis. 


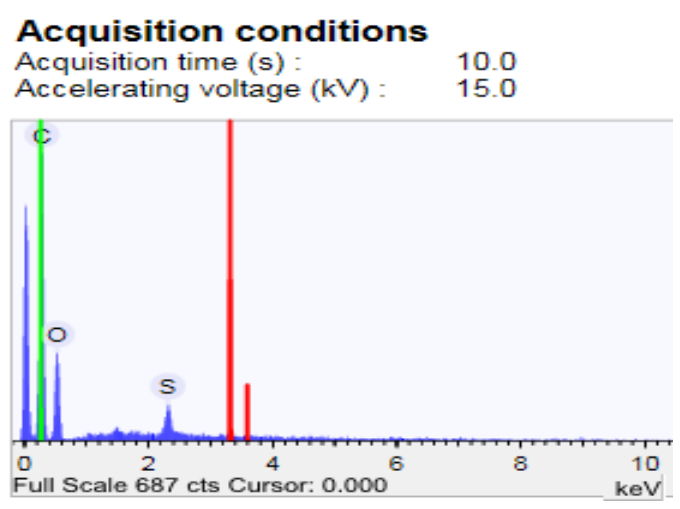

Gambar 3. Spektrum komposisi oksida grafit hasil síntesis

Pada Gambar 4. diperlihatkan perbedaan pola XRD pada serbuk grafit dan pola XRD oksida grafit (GO), serta pola XRD sampel GO yang diberi perlakuan pemanasan pada berbagai suhu. Tampak bahwa serbuk grafit memiliki puncak difraksi pada $26,5^{\circ}$, sesuai dengan yang telah dilaporkan sebelumnya [8], 26,54 ${ }^{\circ}$ [9], 26,56 [10]. Setelah dioksidasi menjadi GO, puncak difraksi tersebut hilang yang menunjukkan struktur GO yang diperoleh berbeda dengan serbuk grafit yang berbentuk kristal. Pada penelitian sebelumnya dilaporkan bahwa puncak difraksi pada GO terletak pada $10,5^{\circ}$ [8].

Jika diamati dengan seksama, pola difraksi GO memiliki puncak di dekat $10^{\circ}$, yang diperkuat oleh sampel yang diberi perlakuan pemanasan. Ketika sampel dipanaskan $100{ }^{\circ} \mathrm{C}$ (GO100), bentuk pola difraksi sama seperti pola GO tanpa perlakuan pemanasan. Setelah suhu pemanasan ditingkatkan menjadi $150{ }^{\circ} \mathrm{C}$ (GO150), puncak difraksi tersebut bergeser ke posisi $10,94^{\circ}$. Posisi puncak difraksi tersebut dekat dengan posisi yang telah dilaporkan sebelumnya yaitu $10,5^{\circ}[8]$.

Hasil ini mengkonfirmasikan bahwa produk GO yang dihasilkan merupakan oksida grafit. Ketika suhu pemanasan tersebut terus ditingkatkan menjadi $350{ }^{\circ} \mathrm{C}$ (GO350) terjadi pergeseran puncak difraksi yang mendekati puncak grafit kembali. Namun ketika pemanasan ditingkatkan menjadi $500{ }^{\circ} \mathrm{C} \quad$ (GO500) struktur sampel tidak dapat diidentifikasi, yang mungkin berkaitan dengan kondisi degradasi dari sampel GO.

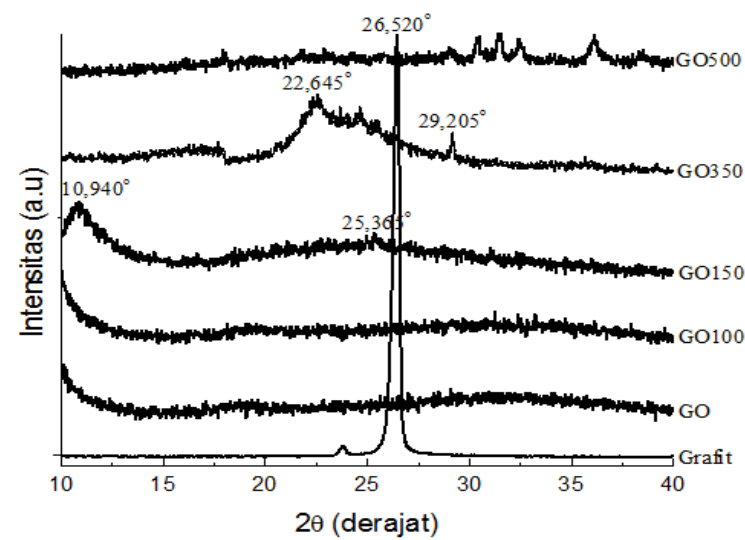

Gambar 4. Pola difraksi GO dibandingkan dengan grafit dan sampel GO yang diberi perlakuan pemanasan.
Gambar 5. menunjukkan spektrum FTIR dari grafit, oksida grafit, dan oksida grafit yang diberi perlakuan pemanasan. Gugus-gugus fungsional oksigen pada produk GO hasil sintesis terlihat muncul pada puncakpuncak transmitansi sekitar bilangan gelombang 3400 $\mathrm{cm}^{-1}$ yang menunjukkan adanya ikatan $\mathrm{O}-\mathrm{H}$. Hal ini menandakan adanya molekul air dan gugus fungsi hidroksil pada sampel. Vibrasi pada sekitar bilangan gelombang $1700 \mathrm{~cm}^{-1}$ berkaitan dengan ikatan $\mathrm{C}=\mathrm{O}$ yang berkaitan dengan gugus karboksil yang terletak pada tepi lapisan GO. Selain itu tampak pula adanya gugus fungsi keton dan kuinon. Selanjutnya vibrasi pada bilangan gelombang $1200 \mathrm{~cm}^{-1}$ dan $1050 \mathrm{~cm}^{-1}$ berkaitan dengan kehadiran ikatan $\mathrm{C}-\mathrm{OH}$ dan $\mathrm{C}-\mathrm{O}$.

Spektrum FTIR grafit sudah menunjukkan kehadiran ikatan oksigen seperti $\mathrm{O}-\mathrm{H}, \mathrm{C}=\mathrm{O}$, dan $\mathrm{C}-\mathrm{O}$ walaupun nilaiya rendah. Ikatan oksigen mungkin berasal dari $\mathrm{KBr}$ yang digunakan saat pembuatan pellet. $\mathrm{KBr}$ memiliki sifat mudah larut dalam air dan higroskopis sehingga mudah menyerap molekul air dari lingkungannya.

Perbandingan spektrum FTIR oksida grafit dan oksida grafit yang mendapatkan perlakuan panas $100^{\circ} \mathrm{C}$ dan 150 ${ }^{\circ} \mathrm{C}$ (GO100 dan GO150) memiliki struktur yang mirip dan hampir tidak ada perubahan struktur yang signifikan. Puncak-puncak transmitansi dengan kekuatan ikatan yang relatif sama menandakan ikatan oksigen pada suhu pemanasan dibawah $150{ }^{\circ} \mathrm{C}$ tidak terlalu terganggu. Kehadiran ikatan $\mathrm{C}-\mathrm{OH}$ pada posisi $1200 \mathrm{~cm}^{-1}$ menandakan keberhasian proses oksidasi grafit. Namun ketika suhu pemanasan ditingkatkan hingga $350{ }^{\circ} \mathrm{C}$, ikatan $\mathrm{C}-\mathrm{OH}$ menghilang dan ketika pemanasan ditingkatkan hingga $500{ }^{\circ} \mathrm{C}$ muncul ikatan $\mathrm{C}=\mathrm{C}$ pada $1560 \mathrm{~cm}^{-1}$. Hal tersebut menunjukkan pada kondisi grafit masih terdapat ikatan rangkap karbon dalam struktur aromatik, namun karena proses oksidasi dan pemanasan struktur aromatik tersebut terputus dan terbentuklah gugus-gugus fungsional oksigen. Ketika dilakukan pemanasan hingga $500{ }^{\circ} \mathrm{C}$, ikatan oksigennya terlepas dan karbon kembali membentuk ikatan rangkap karbon dengan struktur aromatiknya.



Gambar 5. Spektrum FTIR sampel GO dibandingkan dengan grafit dan sampel GO yang diberi perlakuan pemanasan 
Selanjutnya perbandingan spektrum absorbsi dari dispersi oksida grafit hasil sintesis dan oksida grafit hasil sonikasi diperlihatkan pada Gambar 6. Gambar ini menunjukkan sampel GO yang didispersikan (sebelum (a) dan sesudah (b) sonkasi) memiliki puncak utama absorbansi disekitar panjang gelombang $230 \mathrm{~nm}$ dan kurva bahu spectrum disekitar panjang gelombang 297 nm. Puncak transmitansi disekitar $230 \mathrm{~nm}$ muncul karena berhubungan dengan transisi $\pi \rightarrow \pi^{*}$ yang menunjukkan ikatan $\mathrm{C}=\mathrm{C}[10]$.
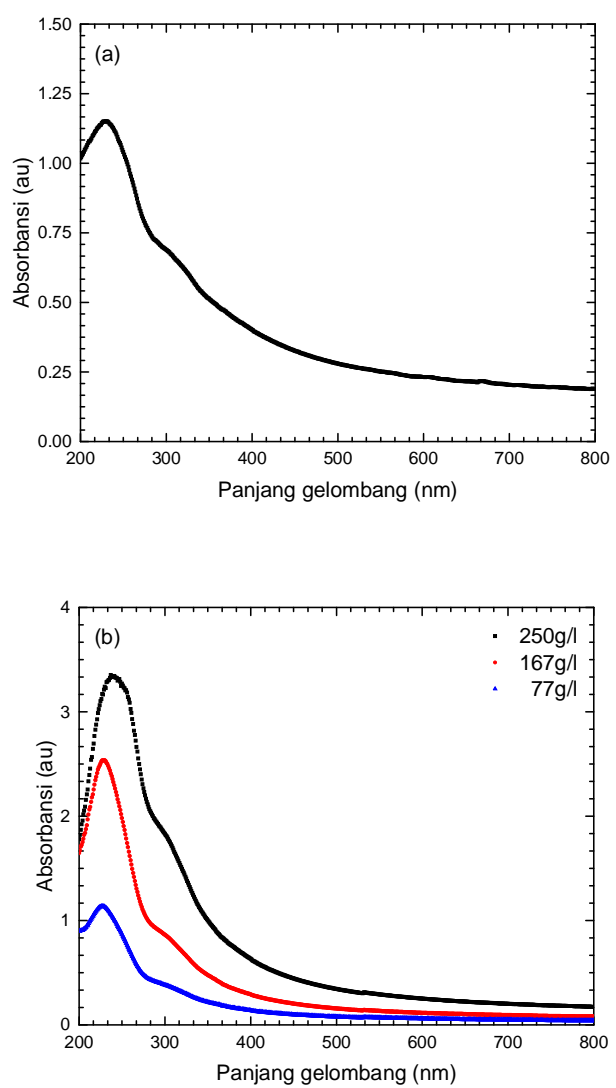

Gambar 6. Spektrum UV-Vis sampel GO hasil síntesis (a) dibandingkan dengan sampel GO yang disonikasi dan sentrifugasi (b) pada konsentrasi berbeda.

\section{KESIMPULAN}

Hasil karakterisasi sampel serbuk menunjukkan telah terjadi perubahan struktur grafit dengan terbentuknya gugus-gugus fungsional oksigen. Hasil pengukuran EDS menunjukkan produk GO yang dihasilkan memiliki perbandingan atom karbon dan oksigen $(\mathrm{C} / \mathrm{O})$ sebesar 2,3 , yang mengkonfirmasi proses oksidasi grafit telah berlangsung dengan baik. Selanjutnya, hasil karakterisasi XRD menunjukkan sampel GO memiliki struktur amorf. Hasil pengukuran FTIR menunjukkan perubahan struktur ikatan pada setiap sampel GO. Gugus-gugus fungsional oksigen pada GO yang dapat diidentifikasi adalah ikatan $\mathrm{O}-\mathrm{H}, \mathrm{C}=\mathrm{O}, \mathrm{C}-\mathrm{OH}$ dan $\mathrm{C}-\mathrm{O}$.

\section{UCAPAN TERIMA KASIH}

Penelitian ini didanai oleh Hibah Kerjasama Luar Negeri kontrak no. 393/UN.R/PL/2015, tanggal 16 Pebruari 2015.

\section{PUSTAKA}

[1] K. S. Novoselov, A. K. Geim, S. V. Morozov, D. Jiang, Y. Zhang, S. V. Dubonos, I. V. Grigorieva, and A. A. Firsov, Electric field effect in atomically thin carbon films, Science, vol. 306, no.5696, 2004, pp. 666-669.

[2] R. R. Nair, et al., Universal Dynamic Conductivity and Quantized Visible Opacity of Suspended Graphene. Science, vol.320, 2008, pp. 1308-

[3] C. Lee, X. Wei, J. W. Kysar, J. Hone, Measurement of The Elastic Properties and Intrinsic Strength of Monolayer Graphene. Science, vol. 321, no.5887,2008, pp. $385-388$.

[4] Bolotin, K. I. et al., Ultrahigh Electron Mobility In Suspended Graphene. Solid State Communications, vol.146, no.9, 2008, pp. $351-355$.

[5] A. A. Baladin, et al., Superior Thermal Conductivity of Single-Layer Graphene. Nano Letters, vol. 8, no.3, 2008, pp. $902-907$.

[6] Shao, G. et al., Graphene Oxide: The Mechanisms of Oxidation and Exfoliation. Journal of Materials Science, 47(10), 2012, pp. $4400-4409$

[7] Hummers, W. S. \& Offeman, R. E., Preparation of Graphitic Oxide. American Chemical Society, vol. 80, no. 6, 1958, pp. 1339-

[8] M. Naebe, et al., Mechanical Property and Structure of Covalent Functionalised Graphene/Epoxy Nanocomposites. Scientific Reports, vol 4, no.3 , 2014, pp. 4375-

[9] Shao, G. et al., Graphene Oxide: The Mechanisms of Oxidation and Exfoliation. Journal of Materials Science, 47(10), 2012, pp. 4400 - 4409

[10] Huang, N. et al., Simple Room-temperature Preparation of High-yield Large-area Graphene Oxide. International Journal of Nanomedicine, vol.6, 2011, pp. $3443-3448$ 